\title{
EXERCÍCIOS FÍSICOS E SEUS BENEFÍCIOS À SAÚDE MENTAL: INTERSECÇÕES ENTRE A EDUCAÇÃO FÍSICA E A PSICOLOGIA
}

\author{
PHYSICAL EXERCISES AND THEIR BENEFITS TO MENTAL HEALTH: \\ INTERSECTIONS BETWEEN PHYSICAL EDUCATION AND PSYCHOLOGY
}

\author{
Marcelo Luis Grassi Beck ${ }^{1}$ \\ Josiane Magalhães ${ }^{2}$
}

RESUMO: A atividade física, além de seus benefícios mais conhecidos, como os circulatórios, cardíacos, imunológicos, etc., tem uma série de benefícios psíquicos, tanto no funcionamento cerebral como na estrutura psíquica da pessoa. Este artigo tem o objetivo de apresentar algumas interfaces entre a atividade física e os estudos acerca das contribuições para a melhora em processos depressivos e na diminuição do stress. Apresenta as possibilidades do exercício físico na direção de uma melhor qualidade de vida e na definição da autoestima e o autoconceito. | Discute tais processos psíquicos em sua relação com os processos de ensino-aprendizagem, atuando na construção de espaços que visem a melhora das estruturas cerebrais. Este artigo busca mostrar a importância do profissional de educação física e da atividade física enquanto instrumentos para promoção e manutenção da saúde cognitiva e psíquica das pessoas.

PALAVRAS-CHAVE: educação física, depressão, stress, aprendizagem.

ABSTRACT: The physical activity, in addition to its more well-known benefits, such as circulatory, cardiac, immunological, etc., has a number of psychic benefits, both in the brain's functioning and in the psychic structure of the person. This article shows the interfaces between physical activity and the studies about its contributions to the improvement in depressive processes and stress reduction. It shows the possibilities of physical exercise towards a better quality of life and on the definition of self-esteem and self-concept. It discusses such psychic processes in its relation with the teaching-learning process, acting on the construction of spaces that aim to improve the brain structures. This article aims to show the importance of the physical educator

\footnotetext{
${ }^{1}$ Doutor em Educação pela UNESP (Universidade Estadual Paulista).Professor Adjunto da Universidade do Estado do Mato Grosso - área Psicologia.Vice Coordenador do Núcleo de Estudos em Ciências Humanas. mlgbeck@ig.com.br

${ }^{2}$ Doutora em Educação pela Universidade Estadual Paulista (UNESP). Professora Adjunta da Universidade do Estado do Mato Grosso - área Sociologia. Coordenadora do Núcleo de Estudos em Ciências Humanas. jopelelu@gmail.com
}

Rev. Fac. Educ. (Univ. do Estado de Mato Grosso), Vol. 28, Ano 15, № 2 p. 129-148, jul./dez. 2017 
and the physical activity as tools for the promotion and maintenance of the cognitive and psychic health of people.

KEYWORDS: physical education, depression, stress, learning.

\section{A prática da atividade física, a melhora na qualidade de vida e a importância do profissional de educação física.}

No Brasil, segundo dados do IBGE (2015), o percentual de pessoas com mais de 15 anos que praticam atividades físicas durante o tempo livre alcançou 37,9\%. Dos 91.142 entrevistados com mais de 15 anos e de todas as regiões do país, os que se declararam não sedentários foram $53,9 \%$ são homens e $46,1 \%$ mulheres.

Pode perceber-se que atualmente a atividade física tornou-se um elemento importante da vida em sociedade, seja na prevenção de doenças, melhora das condições de vida ou por questões estéticas e interações sociais.

Considerando-se a atividade física em seus aos aspectos morfofisiológicos, pode-se dizer que não só é importante mas é essencial à vida. Ela estimula o sistema imunológico, fortalece os músculos, melhora a oxigenação em todo o corpo, evita doenças que afetam o sistema circulatório, além de melhorar o sistema cardiovascular.

Especificamente em relação às doenças que afetam o sistema circulatório, podendo ser obstruções totais ou parciais que geralmente acometem os membros inferiores, pode-se dizer que as atividades físicas são fundamentais. Há na sociedade atual uma preocupação crescente com as enfermidades do trato circulatório e cardiovascular, tendo sido proposto recentemente, um plano de Prevenção e Reabilitação Cardiovascular para a América Latina, bem como prescrita pela medicina uma série de medidas a serem adotadas como protocolos acerca do processo de reabilitação de pacientes. (HERDY et al, 2014); (CABRAL et.al.,1997).

A atividade física promove também benefícios no que chamamos de saúde psíquica ou mental, a qual envolve certo equilíbrio de emoções, o controle do stress, a obtenção de prazer na vida. Ela também beneficia aqueles que já estão na fase de exaustão do stress, em depressão ou com crises de ansiedade. O indivíduo que se encontra desta forma, terá redução na sua capacidade de aprender e memorizar, e nisto e em outros fenômenos a atividade física pode auxiliar na manutenção ou recuperação da saúde psíquica. 
Os profissionais da educação física podem ter um importante papel na prevenção deste tipo de evento ou coadjuvar tratamentos fisioterápicos. Pode parecer que esta atuação dar-se-ia apenas com idosos em asilos e albergues ou pacientes hospitalizados. Na verdade, todos aqueles que necessitam de reabilitação física ou de atividades especiais podem ser alvo de profissionais de educação física, respeitando , é claro, o próprio nível de especialização e as esferas de intervenção profissionais. Principalmente se considerados dentro dos aspectos da atividade física como prevenção de morbidades e gerando hábitos de vida mais saudáveis na população.

De acordo com (GALLO et al, 1995) e (ROLIM,2005), a atividade física pode reverter o retardar de um processo patológico em andamento. Isto porque é uma atividade que envolve processos biológicos bastante complexos, independente de ser decorrente de uma atividade desportiva ou ligado ao trabalho profissional.

A intervenção d e um profissional de educação física, mesmo mesmo que esteja mais vinculada á prevenção, pode ter também um papel terapêutico com aqueles mais debilitados. Ocorre que, este profissional, encontra-se mais habilitado para levar a pessoa a mover-se com prazer, divertindo-se enquanto se fortalece, por ser esta uma preocupação levada em consideração quando se verifica as competências e habilidades a ser desenvolvidas pela área em seu processo de capacitação e do próprio curso de formação do profissional de educação física. A ludicidade é fundamental para que o ser humano aja com motivação. A grosso modo, podemos dizer que a maior parte do comportamento humano busca obter prazer (diversão, companheirismo, amor, sexo, alimentos saborosos, etc.) e evitar a dor (física, decepções nas relações pessoais, frio e calor excessivos, fome e sede, entre outros). Desta forma, observa-se um importante papel da educação física como disciplina, adicionando, prazer, diversão, criando bons hábitos em relação à atividade física, o que propiciará mais saúde mental e física, tanto nos escolares como em muitas outras categorias de pessoas. Este texto procura contribuir para a reflexão entre os benefícios das atividades físicas quando articuladas ao combate ao stress e a manutenção da saúde psíquica.

\section{A atividade física, stress e a saúde psíquica}

Pretende-se enfocar a relação da educação física em sua relação com o autoconceito e a autoestima, com o stress, a ansiedade e depressão, enfocando principalmente sua importância para os escolares. 


\section{Stress}

As discussões sobre o stress ou estresse popularizaram-se e geraram diversos sentidos e definições acerca da percepção que o senso comum constrói sobre seu significado.Vejamos algumas definições:

Estresse - Noção tomada da física e que designa a pressão excessiva sofrida por um material. Em biologia, esta noção designa, ao mesmo tempo, as agressões exercidas sobre o organismo (os agentes estressantes) e a reação do organismo às agressões. Essa reação é não específica, o que quer dizer que ela não depende do agente agressor ou estressante(...). Em psicologia o termo estresse é empregado para evocar as múltiplas dificuldades que o indivíduo tem problema para enfrentar os acontecimentos estressantes da vida, também chamados acontecimentos vitais e os meios de que dispõe para administrar esses problemas (as estratégias de ajustamento)(DORON \&PAROT,1998, p.316)

Estresse - estado de resposta fisiológica ou psicológica a estressores internos ou externos. $O$ estresse envolve alterações afetando quase todos os sistemas do corpo, influenciando como as pessoas se sentem e se comportam. Por exemplo, ele pode ser manifestado por palpitações, sudorese, boca seca, falta de ar, inquietação, fala mais rápida, aumento de emoções negativas (se já estão sendo vivenciadas) e duração mais longa por estresse. $O$ estresse severo é manifestado pela SíNDROME DE ADAPTAÇÃO GERAL. Ao causar essas alterações mentais e corporais, o estresse contribui diretamente para transtorno e doença psicológica e fisiológica e afeta a saúde mental e física, reduzindo a qualidade de vida. [descrito primeiramente no contexto da psicologia por volta de 1940 pelo médico canadense Hans Selye.] (APA,2010 p.385-386)

Pelas definições exemplificadas, percebe-se que o stress não tem só um funcionamento negativo, aliás, a razão para a existência desse fenômeno, esse encadeamento de reações orgânicas, está na proteção do indivíduo. Considerado um fruto da evolução humana, o stress tem a função de otimizar os recursos biológicos, de forma dramática e temporária, para que os indivíduos consigam praticar o chamado mecanismo de Luta ou Fuga. Este é considerado o mecanismo que permite enfrentar as ameaças, principalmente físicas, por 
exemplo, correndo-se mais rápido que o normal, com o uso de força física maior, com maior capacidade de atenção e melhor memória, sangrando menos e sentindo-se menos dor se feridos. (CRAKE; BARLOW, 1994)

Este foi um mecanismo muito útil numa existência exposta a predadores e condições físicas ambientais muito difíceis, porém, o stress tornou-se nos dias de hoje menos necessário e, às vezes, inconveniente. Infelizmente a abundância de fatores desencadeantes de stress na vida moderna pode levar a inúmeros problemas físicos e psíquicos. Bombardeado por problemas e desafios, inundado pelos hormônios liberados, o ser humano e seu corpo tentam adaptar-se, o que nem sempre é possível. É mais correto dizer então que não o stress em si, mas o stress crônico, aquele que cuja freqüencia e/ou intensidade desequilibra diversos sistemas do organismo, inclusive o sistema nervoso, tornando-se danoso.

[...] as pessoas que sofrem de estresse intenso ou contínuo podem desenvolver problemas cardiovasculares, como ataques cardíacos, ou 'endurecimento das artérias', conhecido como aterosclerose - um fator de risco para ataques cardíacos quanto para acidentes vasculares cerebrais. $O$ estresse crônico pode prejudicar o sistema imunológico, tornando as pessoas mais suscetiveis a resfriados e infecções; também pode elevar a reação imunológica a níveis perniciosos, resultando em alergias, asma e estados autoimunes. A própria mente pode ser uma vítima do estresse se sentimentos de angústia e desânimo tenderem para a depressão clínica ou ansiedade. Há mesmo evidência de que a depressão e o estresse traumático podem causar atrofia em partes do cérebro. (MCEWEN\& LAISLEY, 2003, p.17-18)

Os malefícios do stress crônico ou excessivo já estão bem estabelecidos por inúmeras pesquisas. A par desses achados, a questão que se coloca é como a atividade física e a educação física se colocam neste contexto? Poderia a simples prática desportiva ou de exercícios contribuir para a saúde mental do praticante?

Pesquisas recentes sobre o tema têm vinculado à atividade física a ganhos significativos no combate ao stress. Além da já bem estabelecida descarga de endorfina, liberada em função da atividade física e com efeito relaxante sobre o estado de ansiedade, outros efeitos surpreendentes vêm sendo descobertos.

Segundo (MATSUDO, 2009), são efeitos benéficos, cognitivos e psi- 
cossociais, da atividade física para a saúde humana:

melhora no autoconceito, autoestima, imagem corporal, estado de humor, tensão muscular e insônia;

prevenção ou retardo do declínio das funções cognitivas;

diminuição de risco de depressão;

diminuição do estresse, ansiedade, depressão, do consumo de medicamentos e incremento da socialização (MATSUDO, 2009, p.05).

Pesquisas com animais, principalmente ratos e camundongos, vem mostrando que a atividade física estimula a neurogênese (formação de novos neurônios) no hipocampo, região responsável por parte considerável da memória e do equilíbrio emocional.

Estas descobertas estabelecem uma relação inequívoca entre atividade física e a melhora de capacidades cognitivas, pois a memória é fundamental para a retenção da aprendizagem e posterior evocação da mesma para propiciar o raciocínio lógico e emocional.

O stress tem a característica de eliminar neurônios e a atividade física, portanto, beneficia o funcionamento cerebral por ajudar a preservar a integridade neuronal.

Até pouco tempo acreditava-se que os humanos e os animais superiores nasciam com todos os neurônios que teriam ao longo da vida, ou seja, seu número só decresceria desde o nascimento. Em pesquisa realizada com ratos e camundongos por (MCEWEN \& LASLEY, 2003) os autores constataram que em algumas áreas do cérebro há o surgimento de novos neurônios, embora em quantidade limitada. Estes estudos descobriram que um meio ambiente enriquecido proporcionava aumento nas conexões sinápticas, as vias que permitem a comunicação entre os neurônios e bem como um aumento na neurogênese. Ainda segundo este estudo alguns fatores eram os principais responsáveis pelo nascimento de neurônios, entre elas estava o exercício físico. Os outros se inseriam na interação social com outros animais, estimulação mental sobre forma de treinamento e labirintos e o fornecimento de respostas com a oferta de guloseimas extras, como maçãs e queijo.

(GAGE,1999) em outro experimento buscou verificar que fator teria maior influência na neurogênese. Separou o meio ambiente enriquecido em componentes. Alguns camundongos foram colocados em gaiolas com acesso irrestrito a todas as rodas de exercício, outros eram forçados a nadar como exercício, alguns foram treinados em um labirinto aquático e outros tiveram 
acesso a todo o ambiente enriquecido, fazendo todas as coisas e havia um grupo controle em gaiolas simples. Este estudo verificou que os camundongos que corriam nas rodas sempre que queriam tiveram um aumento significativo na neurogênese no hipocampo e as células obtidas sobreviviam em maior número até a idade adulta e até serem operacionais.

Pesquisas como essas demonstram a importância da atividade física para o desenvolvimento e preservação neurológica. Considerando o stress, devemos lembrar que, dentre a cascata de hormônios liberados está o cortisol. Este hormônio, em grandes quantidades, destrói neurônios no hipocampo, região cerebral ligada á memória e emoções. Liberações muito repetitivas ou intensas demais produzem danos a este, tendo inclusive a capacidade de destruir grande parte do mesmo, conforme descobriram estudos em veteranos de guerras ou de mulheres mantidas cativas como escravas sexuais em campos de concentração sérvios, por meses, durante a guerra da Bósnia, na década de 1990. Esse fenômeno, chamado de Stress Pós-Traumático é dramático pelo sofrimento mental que propicia, com depressão e alta ansiedade permanentes e sem um tratamento que propicie uma cura definitiva. Usamos estes exemplos para ilustrar o poder de destruição do cortisol liberado pelo stress em excesso.

É claro que não se espera que a atividade física possa reverter efeitos tão dramáticos no cérebro, porém, ela pode auxiliar no controle da ansiedade e depressão através da liberação de hormônios como a endorfina, de efeito relaxante e tranquilizador e no contato social que propicia. Já, no stress "normal" do dia a dia, a atividade física pode ter um papel mais efetivo, reduzindo danos ao hipocampo e como importante meio preventivo de transtornos psíquicos como a depressão.

O estudo citado demonstra também que o exercício voluntário e prazeroso é mais eficiente. Falamos anteriormente que a ludicidade, o prazer, é muito importante para que o indivíduo aja, se mova. É o melhor tipo de motivação, gera a atividade corporal necessária ao bem estar físico e psíquico. Contudo, esse prazer associado à atividade física não deve ser apenas fruto de uma atividade individual e mais dependente de circunstâncias favoráveis. Ele deve ser provocado, estimulado e as atividades que o propiciem devem ser ensinadas, para virarem hábitos. A psicologia mostra que hábitos não são fáceis de ser abandonados, sejam bons ou ruins.

Neste momento reafirma-se a importância do profissional de educação física, seja em escolas, hospitais, asilos ou clubes esportivos. Ele tem o desafio de, além das técnicas desportivas e dos exercícios físicos, despertar o prazer nessas atividades. Entre idosos e escolares isso é observável. Não que o 
atleta não deva obter prazer de suas atividades. Ele terá melhor desempenho se o tiver, contudo, há outras motivações agindo, como a superação de metas e desafios e, em muitos casos a disputa profissional e questõesfinanceiras. Para a maioria das pessoas o prazer é fundamental ou pelo menos deve haver a eliminação de grande parte do desprazer. Fazer o indivíduo que joga bem futebol ter prazer é fácil. O simples reforço que obtém através da admiração que ele conquista permite isso. Mas, como tornar a mesma atividade prazerosa para o estudante com dificuldades de peso, com motricidade e condicionamento notadamente inferiores e com as mais variadas diferenças, talvez até de identificação de gênero? Como impedir que as atividades de educação física não sejam um pesadelo, desenvolvam trauma? Como promover a aceitação grupal e melhorar a autoestima do estudante se, às vezes, os próprios professores os discriminam?

Em termos educacionais, o maior de desafio para educadores é conseguir alavancar o prazer durante o processo de ensino-aprendizagem. É preciso, além dos conhecimentos mais afeitos às disciplinas, conhecer (isto é um processo) as particularidades das categorias e tipos de estudantes. $O$ extrovertido e o tímido, como eles se comportam, mas também quais fenômenos podem ter contribuído para o desenvolvimento de seus comportamentos naturais. Isto se obtém em um processo permanente, pelo estudo, pela observação, pelo ouvir o estudante, pelas tentativas e reavaliações e pelas experiências dos outros profissionais.

\section{Atividade física: autoconceito e autoestima}

Autoconceito e autoestima são construtos da Psicologia que representam e permitem analisar a visão que o indivíduo tem de si, de seus atributos, quer considere-os positivos ou negativos e os sentimentos que vivencia em função disto. Embora exista certa confusão terminológica e classificações diferentes, a maioria dos autores considera o autoconceito como a parte avaliativa racional, e a autoestima como os sentimentos que vivencia em função da forma como se avaliou, embora não seja possível dissociar concepções racionais e emoção, elas interagem o tempo todo. A autoimagem, embora construto de outra fonte representa mais ou menos o autoconceito e a autoestima também é usada popularmente como representação conjunta, tanto do autoconceito como da autoestima, a avaliação racional e sentimental que temos de nós mesmos.(AMERICAN PSYCHOLOGICAL ASSOCIATION, 2010). Nas palavras do 
dicionário da American Psychological Association:

\begin{abstract}
Autoconceito - a concepção e a avaliação da pessoa de si mesma, incluindo características psicológicas e físicas, qualidade e habilidade. $\mathrm{O}$ autoconceito contribui para o senso de identidade do indivíduo com o passar do tempo. [...] embora autoconceito esteja geralmente disponível à consciência em algum grau, ele pode ser inibido de representação, contudo pode ainda influenciar o julgamento, humor e padrões comportamentais. Também denominado autoavaliação; autoclassificação.(AMERICAN PSYCHOLOGICAL ASSOCIATION, 2010, p.116)
\end{abstract}

Autoestima- o grau com que as qualidades e características contidas no autoconceito da pessoa são percebidas como positivas. Ela reflete a autoimagem física de uma pessoa, a visão de suas realizações e capacidades e os valores e sucesso percebido em viver a altura delas, bem como as formas que os outros vêem e respondem aquela pessoa. Quanto mais positiva a percepção dessas qualidades e características, mais alta a autoestima da pessoa. (AMERICAN PSYCHOLOGICAL ASSOCIATION, 2010, p.118)

O autoconceito de uma pessoa possui algumas fontes. A primeira, que começa quando ainda somos bebê, é a visão que os outros têm e demonstram a nosso respeito. Se somos, "bons meninos", " garotos levados " ou " estorvo na vida dos outros". Essas primeiras impressões são fundamentais para a visão que o indivíduo terá de si e para o respeito e amor-próprio que terá. Outra fonte de autoconceito é a análise de nosso papel e status no mundo, feita por nós próprios. Observo os outros, comparo seu desempenho com o meu e, com base nas normas e valores sociais e familiares concluo o quanto sou inteligente e, se isto é suficiente. O quanto sou rápido, o quanto sou forte, o quanto sou atraente, o quanto sou bom em matemática, etc. Todos sabemos que esse tipo de avaliação nos torna mais ou menos orgulhosos de nós mesmos e sentir emoções boas ou ruins em seguida é inevitável.

Esse mecanismo de avaliação de si próprio é permanente, dura a vida inteira e pode também ser influenciado por fatores orgânicos. Pessoas em depressão ou com "estilos depressivos" de avaliação de si e do mundo terão percepções tendenciosas da realidade, isto por influência dos desequilíbrios na quantidade de neurotransmissores no cérebro. 
O autoconceito pode ser definido como uma estrutura cognitiva que organiza as experiências passadas do indivíduo, reais ou imaginárias, controla o processo informativo relacionado consigo mesmo e exerce uma função de autoregulação (...) [diversos autores] descrevem o autoconceito como as representações mentais das características pessoais utilizadas pelo indivíduo para a definição de si mesmo e regulação do seu comportamento. As representações mentais de que falam os autores têm sido também denominadas esquemas cognitivos ou auto-esquemas. Os esquemas, (...) moldam as percepções que os indivíduos possuem das situações, suas memórias dos eventos e seus sentimentos sobre si mesmos e sobre os outros(...) Os auto-esquemas resumem as experiências passadas do indivíduo e organizam a ampla variedade de informações relativas a si mesmo (MARKUS, CRANE, BERNSTEIN \& SILADI, 1982) apud (TAMAYO Et Al., 2001 p.158)

Os esquemas que o indivíduo adquire e, com os quais se avalia são passíveis de alteração durante toda a vida, mas isto não ocorre de forma simples ou fácil, pelo menos naqueles mais estruturantes e que reflitam áreas que ele julgue mais importantes. Um autoconceito negativo deve ser alvo de ações por parte da Psicologia, das famílias e dos profissionais da educação. Muitos estudantes que evitam tarefas e participações não são preguiçosos, se é que os outros o são, mas tem uma ação evitativa do fracasso que, acreditam, irá acontecer. Tem medo do vexame público e de sentir novamente vergonha e confirmar suas "certezas íntimas" de inferioridade. Por isso, a escola deve estar bastante atenta às particularidades históricas e psíquicas de seus estudantes, capacitando seus profissionais para a observação e intervenção positiva.

Apesar de termos uma espécie de "autoconceito global", uma avaliação geral mais ou menos positiva de nós mesmos, adquirimos também autoconceitos específicos. Podemos ter um autoconceito acadêmico, que pode se subdividir em autoconceito em matemática (como sou bom ou não nesta disciplina), autoconceito em geografia, etc. Temos autoconceitos familiares (como sou como filho, como sou como marido, etc.). Temos autoconceitos religiosos, entre outros.

Um tipo de autoconceito que tem muito a ver com as atividades escolares de educação física é o autoconceito sobre a aparência e habilidades físicas que o estudante adquiriu. Todas as crianças do mundo adquirem uma avaliação de sua aparência física em relação às aparências dos outros e se elas são melhores adaptadas àqueles modelos ou padrões mais aceitos e mais 
valorizados numa determinada sociedade.

Ter uma aparência física invejável, bem como ter desenvolvido habilidades físicas e atléticas aprovadas e esperadas pelo grupo no qual o indivíduo vive, afeta grandemente seu autoconceito (visão de si) e sua autoestima (os sentimentos que vivencia a partir dessa avaliação). Vivemos numa sociedade na qual o respeito ao que é diferente ou não tão bem habilitado representa um alvo a ser atingido, uma concepção ainda por ser implantada nas mentes de todas as crianças.

Infelizmente o medo, a rejeição e a perseguição dos diferentes, seja fisicamente, seja intelectualmente, financeiramente, sexualmente e muitos outros ainda existe em enormes quantidades. Um estudante que se avalie como inferior no desempenho físico em relação aos seus colegas vivenciará sentimentos de vergonha e inferioridade por ação do mecanismo de comparação. Se, o mesmo, ainda sofrer gozações e discriminações por parte da turma (como o tradicional ser escolhido sempre para goleiro ou gandula nas partidas de futebol), o sofrimento psíquico pode ser muito alto. O estudante tenderá a evitar as atividades, pois fracassar provoca sofrimento e queda na autoestima e, ele "sabe" que vai fracassar. Como tentativa de adequar-se mais e, portanto, sentir-se menos excluído, a criança com baixo autoconceito tenta passar uma imagem de si irreal e fantasiosa, na tentativa de ser melhor aceito, menos alvo das chacotas e sentir menos vergonha de si.

O componente cognitivo está constituído pelas percepções que o indivíduo tem dos traços, das características e das habilidades que possui ou que pretende possuir. $\mathrm{O}$ componente comportamental consiste nas estratégias de auto-apresentação utilizadas pelo indivíduo, com o objetivo de transmitir aos outros uma imagem positiva de si mesmo (Schlender, Dlugolecki \& Doherty, 1994). Estes três componentes, avaliativo, cognitivo e comportamental são diferentes, mas estão relacionados entre si. Assim, uma pessoa que se percebe como tendo características indesejáveis, muito provavelmente se avalia de forma desfavorável, mas tenta se apresentar de forma positiva. (TAMAYO et al._2001, p.158)

Temos nesta situação um desafio bastante mais complexo para o profissional de educação física. Além de promover a saúde, via atividades físicas e ensinar conhecimentos técnicos sobre elas, este profissional precisa adquirir conhecimentos sobre a psicologia e sociologia humanas que Ihe auxiliem na tarefa de tornar os alunos divergentes da média em qualquer comportamento 
ou com desempenho físico inferior, bem aceitos pelos colegas, o que favorecerá muito a própria autoaceitação do aluno. Felizmente, tanto o autoconceito como a autoestima são passíveis de alterações positivas, podem mudar sempre e também para melhor.

Tais componentes não são necessariamente estáveis através do tempo e dos múltiplos eventos que ocorrem na vida cotidiana do indivíduo. Recentemente, Nezlek e Plesko (2001) demonstraram que mudanças diárias na clareza do autoconceito covariam com eventos diários positivos e/ou negativos e com mudanças de humor da pessoa. O conteúdo do autoconceito é determinado tanto pela situação social na qual se encontra o sujeito como pelos seus interesses, metas e motivações do momento.(TAMAYO et al.,2001, p.158)

Escolher atividades ou desenvolvê-las de forma que ninguém se sinta diminuído ou inferiorizado no sentido valorativo, de forma que todos obtenham prazer e alguma evolução é uma arte e esperamos que todas as crianças (e os mais velhos) tenham professores artistas. Aliás, as atividades artísticas e a atividade física têm o poder de melhorar o autoconceito e a autoestima de escolares, debilitados físicos ou em recuperação e idosos, fazendo-os orgulharem-se de feitos e de sua evolução e obterem ganhos em sua esfera cognitiva.

\section{Atividade física e depressão}

Dentre as inúmeras classificações de transtornos mentais a depressão é uma doença que pode ter base genética ou não. Ela é um dos transtornos mentais mais frequentes e pode ter diversos níveis de gravidade, desde uma depressão leve e crônica até aquela chamada de depressão maior, na qual são comuns a desesperança e ideias de suicídio. $O$ stress (leia-se sofrimento afetivo, crises financeiras, decepções, excesso de trabalho, etc.) sempre encontra-se envolvido no desenvolvimento da depressão.

Segundo as estimativas, utilizando a metodologia da Carga Global da Doença, proposta pela Organização Mundial de Saúde, para o ano de 2020, a doença isquêmica do coração e a depressão serão as duas maiores causas não só de mortalidade mas, de incapacidade sobre a população em geral. A depressão é caracterizada 
por tristeza, baixa da autoestima, pessimismo, pensamentos negativos recorrentes, desesperança e desespero. Seus sintomas são, fadiga, irritabilidade, retraimento e ideação suicida. O humor depressivo pode aparecer como uma resposta a situações reais, por meio de uma reação vivencial depressiva, quando diante de fatos desagradáveis, aborrecedores, frustrações e perdas. Trata-se, neste caso, de uma resposta a conflitos íntimos e determinados por fatores vivenciais. A depressão está associada a uma alta incapacidade e perda social. (COSTA,2007 p.01)

As doenças cardíacas e a depressão além de serem responsáveis pelas maiores causas de mortalidade, associam-se também quando pensamos em termos de benefícios que podem ser gerados aos indivíduos se praticar atividade física. Contudo, os benefícios em relação às primeiras já são bem estabelecidos há tempos, enquanto em relação à depressão os estudos são recentes e bastante reveladores da capacidade do exercício alterar a bioquímica cerebral.

A medicação farmacológica antidepressiva apresenta influências positivas no tratamento da depressão, porém muitos pacientes não aderem ou não persistem a esse tipo de tratamento devido aos seus efeitos colaterais e ao seu alto custo. A falta de acesso e persistência ao tratamento farmacológico aumenta a procura por tratamentos antidepressivos alternativos, como eletroconvulsoterapia, psicoterapia e a atividade física (KATZ, 2003; SILVEIRA, 2001). Pesquisas direcionadas à qualidade de vida têm evidenciado cada vez mais a importância da atividade física e do exercício físico à saúde mental. Levantamentos realizados nos EUA e na Inglaterra demonstram que a prática de exercício físico regular apresenta valor terapêutico na redução de sentimentos de ansiedade e depressão (WEINBERG, 2001). A atividade física é um importante aliado do tratamento antidepressivo devido ao seu baixo custo e sua característica preventiva de patologias que podem levar um indivíduo a situações de estresse e depressão. Os estudos que relacionam a atividade física à depressão têm verificado que indivíduos que praticam atividade física de forma regular reduzem significantemente os sintomas depressivos (SHARKEY, 1998). (MATTOS; ANDRADE; LUFT, 2004).

Cerca de trinta por cento dos pacientes com depressão não respondem bem a antidepressivos, ou sofrem efeitos colaterais muito severos, o que 
por si só já habilita a atividade física como um fator coadjuvante de tratamento para esta doença. Um dos possíveis fatores benéficos seria nas atividades em grupo, momento de possível camaradagem e troca de experiências. Como muitos estudos vêm apontando benefícios na atividade física para os deprimidos, vejamos algumas hipóteses que explicam isso:

Muitos estudos apontam à possibilidade de pessoas fisicamente ativas, em qualquer idade, apresentarem uma melhor saúde mental do que sedentários. Entre as hipóteses que tentam explicar a ação dos exercícios sobre a ansiedade e depressão, uma da mais aceita é a hipótese das Endorfinas. A teoria da endorfina sugere que a atividade física desencadearia uma secreção de endorfinas capaz de provocar um estado de euforia natural, por isso, aliviando os sintomas da depressão. Essa ideia, entretanto, não tem consenso entre os pesquisadores. Alguns deles, por exemplo, preferem acreditar que o exercício físico regularia a neurotransmissão da noradrenalina e da serotonina, igualmente aliviando os sintomas da depressão. Outra hipótese seria a cognitiva. De natureza eminentemente psicológica, a hipótese cognitiva se fundamenta na melhoria da autoestima mediante a prática do exercício, sustentando que os exercícios em longos prazos ou os exercícios intensivos melhorariam a imagem de si mesmo e, consequentemente, a autoestima.(MATTOS; ANDRADE;LUFT,2004, p s.n.ㅇ)

A pesquisa de (MATTOS, 2004) ouviu as percepções de quinze psiquiatras em Florianópolis sobre os efeitos que os mesmos observavam em seus pacientes com depressão quando se exercitavam. Eles avaliaram fenômenos ligados à depressão e todos em uma escala de nenhum efeito até efeito total. Vejamos o quadro com seus resultados: 
Quadro 1. Efeito da atividade física sobre o tratamento antidepressivo segundo a percepção de psiquiatras atuantes nas clínicas psiquiátricas da Grande Florianópolis $(n=16)$.

\begin{tabular}{|c|c|c|c|c|c|}
\hline & $\begin{array}{c}\text { Nenhum efeito } \\
(0 \%)\end{array}$ & $\begin{array}{l}\text { Pouco } \\
\text { efeito } \\
(25 \%)\end{array}$ & $\begin{array}{l}\text { Efeito } \\
\text { moderado } \\
(50 \%)\end{array}$ & $\begin{array}{l}\text { Muito efeito } \\
(75 \%)\end{array}$ & $\begin{array}{c}\text { Total } \\
\text { efeito } \\
(100 \%)\end{array}$ \\
\hline $\begin{array}{l}\text { Melhoria da estabilidade } \\
\text { emocional }\end{array}$ & $3(18,8 \%)$ & $1(6,3 \%)$ & $7(43,8 \%)$ & $4(25,0 \%)$ & $1(6,3 \%)$ \\
\hline Imagem corporal positiva & & $1(6,3 \%)$ & $6(37,5 \%)$ & $5(31,3 \%)$ & $4(25,0 \%)$ \\
\hline $\begin{array}{l}\text { Aumento da positividade } \\
\text { psicológica }\end{array}$ & $1(6,3 \%)$ & $2(12,5 \%)$ & $8(50,0 \%)$ & $4(25,0 \%)$ & $1(6,3 \%)$ \\
\hline Diminuição da insônia & & $1(6,3 \%)$ & $5(31,3 \%)$ & $7(43,8 \%)$ & $3(18,8 \%)$ \\
\hline Autocontrole psicológioo & $2(12,5 \%)$ & $3(18,8 \%)$ & $7(43,8 \%)$ & $3(18,8 \%)$ & $1(6,3 \%)$ \\
\hline Melhora do humor & $1(6,3 \%)$ & $1(6,3 \%)$ & $6(37,5 \%)$ & $5(31,3 \%)$ & $3(18,8 \%)$ \\
\hline Interacão social positiva & & $2(12,5 \%)$ & $6(37,5 \%)$ & $4(25,0 \%)$ & $4(25,0 \%)$ \\
\hline $\begin{array}{l}\text { Competência e auto-eficácia } \\
\text { para a realização de tarefas } \\
\text { diárias }\end{array}$ & & $2(12,5 \%)$ & $4(25,0 \%)$ & $7(43,8 \%)$ & $3(18,8 \%)$ \\
\hline Diminuicão da tensão & & & $7(43,8 \%)$ & $4(25,0 \%)$ & $5(3$ \\
\hline
\end{tabular}

Fonte: MATTOS; ANDRADE; LUFT, 2004

Podemos perceber uma concentração nas categorias efeito moderado (50 \%) e muito efeito (75 \%), verificando-se que na opinião dos psiquiatras a atividade física realmente é eficaz na depressão, via melhora de seus sintomas. Apesar das causas não terem sido cientificamente comprovadas, o efeito empírico tem um peso bastante revelador.

O exercício físico tem tido uma importante participação no tratamento da depressão. A atividade física proporciona benefícios físicos e psicológicos como a diminuição da insônia e da tensão, e o bem estar emocional, além de promover benefícios cognitivos e sociais a qualquer indivíduo (KATZ, 2003; OLIVEIRA, 2004). Alguns estudos indicam que o efeito antidepressivo da atividade física pode ser verificado rapidamente, sendo que 3 semanas de algumas seções regulares são suficientes para se perceber a melhora no estado de humor em pacientes com depressão subclínica (BYRNE, 1993;CRAFT, 2004).Tanto nos dados obtidos 
através desta pesquisa como na literatura, percebe-se que na prática profissional o exercício físico é reconhecido como eficaz à saúde mental. (MATTOS;ANDRADE;LUFT,2004 p.s n으)

A experiência clínica vem considerando a atividade física importante não só para o tratamento da depressão e das categorias clássicas da psiquiatria, mas também de manifestações psicológicas as mais variadas.

Considerando que todas as pessoas estão sujeitas a algum tipo de sofrimento, ansiedade, depressão, euforia, tristeza etc., a possibilidade de se estudar a saúde mental através da educação física é bastante satisfatória no sentido das vivências do comportamento humanos nas diversas práticas corporais que é o objetivo da educação física, e é de extrema importância no enfrentamento dos transtornos mentais, uma vez que ajuda o indivíduo portador de transtorno mental perante sua reinserção à sociedade, promovendo a autoestima, propiciando valores socioeducativos e estimulando suas resistências diante das pressões psicoemocionais sofridas no dia a dia.(IBGE,2015)

Verificamos como a atividade física apresenta benefícios para os transtornos mentais mais estabelecidos. Porém, esses mesmos benefícios se estendem as mais variadas esferas das pessoas, inclusive ao universo escolar. Como citado antes, benefícios como melhora do humor, da interação social, da estabilidade emocional e da autoestima, e a diminuição da ansiedade beneficiam os estudantes, favorecendo seu desempenho escolar, o qual é impelido por um estado psicológico mais favorável.

\section{Atividade Física e Educação}

Como vimos anteriormente, a atividade física espontânea e aquela programada pelo profissional de educação física, têm a capacidade de atenuar o nível de stress, diminuindo assim a ansiedade e favorecendo o processamento cognitivo do indivíduo. O mesmo acontece com a depressão, que normalmente sucede um período de stress elevado e cuja tensão, tristeza e desânimo interferem fortemente na motivação para a aprendizagem e na habilidade de raciocinar e usar a memória. Já está bem estabelecido que a maior produção 
de hormônios cerebrais, impelida pelas atividades físicas trazem, não apenas um melhor estar psíquico, mas também ganhos consideráveis para a cognição.

Contudo, a atividade física e o profissional de educação física devem estar sintonizados com os objetivos da escola, os quais incluem desenvolvimento físico, interação social, estruturação emocional e melhora das habilidades cognitivas. O educador precisa ser mais que um profissional de educação física, ele precisa atentar-se para as seguintes dimensões:

[...] toma-se possível falarmos em uma dimensão procedimental, uma dimensão simbólica e uma dimensão atitudinal. A dimensão procedimental diz respeito ao saber fazer, a capacidade de mover-se numa variedade de atividades motoras crescentemente complexas de forma efetiva e graciosa. É importante ressaltar que, nessa concepção, aprender a mover-se envolve atividades como tentar, praticar, pensar, tomar decisões e avaliar, significando portanto, muito mais do que respostas motoras estereotipadas. No que diz, respeito à dimensão atitudinal neste sentido, o movimento é um meio para o aluno aprender sobre seu potencial e suas limitações, além de aprender sobre o meio ambiente. Expressando-se pelo gesto, som, mímica, jogos, o aluno percebe que o corpo é um instrumento de comunicação e através dessa exploração e observação poderá estabelecer comparações com outras crianças, adultos, animais construindo seu autoconceito e a compreensão da realidade. Finalmente, a dimensão simbólica que significa a aquisição de um corpo de conhecimentos objetivos, desde aspectos nutricionais até sócio-culturais como a violência no esporte ou o corpo como mercadoria no âmbito dos contratos esportivos.(FERRAZ,1996, p. 20)

Podemos ver que a educação física propicia bem mais que condicionamento físico e desenvolvimento motor, pois pode promover alterações no senso de identidade dos estudantes, enriquecendo sua autoestima e seu autoconceito. Pode aumentar o repertório simbólico e da aquisição de novos significados os conteúdos já conhecidos. Pode contribuir com suas regras para uma formulação de uma estrutura moral e para a concepção de vida das pessoas.

Pelo que vimos, a atividade física apresenta, entre outros benefícios, vantagens para a esfera educacional e a saúde mental dos praticantes. Seja no combate ao stress, na prevenção e tratamento da depressão, seja no reforço da autoestima e no simples prazer do contato social. Dentro deste panorama encontra-se o profissional de educação física com uma grande área de atuação 
e uma grande responsabilidade, estimulando a prática de uma atividade que proporcionará ganhos muito além dos físicos, mas influindo no processo ensino -aprendizagem, através da autoestima e dos benefícios cognitivos alcançados.

\section{Referências}

AMERICAN PSYCHOLOGICAL ASSOCIATION. Dicionário de Psicologia da Apa. Gary R. Vandebos(org.). Porto Alegre: ARTMED, 2010.

CABRAL, A. P. T. et al. O Estresse e as Doenças Psicossomáticas Revista de Psicofisiologia, 1(1), 1997 Laboratório de Psicofisiologia do Departamento de Fisiologia e Biofísica do Instituto de Ciências Biológicas da UFMG, 1997. Disponível em : <http://www.icb.ufmg.br/lpf > Acesso em: 12.fev.2018.

COSTA, R.A.; SOARES, H. L.R.; TEIXEIRA, J. A.C. Benefícios da atividade física e do exercício físico na depressão. Rev. Dep. Psicol.,UFF, Niterói, v. 19, n. 1, 2007 . Disponivel em: <http://www.scielo.br/scielo.php?script=sciarttext\&pid=S0104-80232007000100022\&Ing=en\&nrm=issohttp://dx.doi. org/10.1590/S010480232007000100022>. Acesso em: 25/01/2018.

CRAKE E BARLOW. Fisiologia e psicologia do medo e da ansiedade, 1994. Disponível em: <http://www.pospsicopatologia.com.br/paula/Paula_Fisiologia_e_Psicologiado_medo_e_da_ansiedade.pdf>. Acesso em: 12/02/2018.

DORON,R; PAROT, F. Dicionário de Psicologia.São Paulo : Editora Ática, 1998.

ERIKSSON, P. S. et al., Neurogenesis in the adult human hippocampus. Nature Medicine, vol. 4, no 11, págs. 1313-1317, novembro de 1998.

FERRAZ,O.L. Educação Física Escolar: conhecimento e especificidade a questão da pré-escola. Re v. Paul. Educ. Fis., São Paulo, supt.2, p.16-22,1996 Disponível em: <Https://www.revistas.usp.br/rpef/article/viewfile/139639/134933>. Acesso em: 25/01/2018.

GOULD, E. et al.Learning enhances adult neurogenesis in the hippocampal formation., em Nature Neuroscience, vol. 2, no 3, págs. 260·265, março de 1999.

GAGE, F.G. Como nascem os neurônios.Mente\&Cérebro, edição 178, novembro de 2007. 
HERDY, et Al. Diretriz Sul-Americana de Prevenção e Reabilitação Cardiovascular .Arq. Bras. Cardiol. vol.103 no.2 supl.1 São Paulo Aug. 2014 disponível em: <http://dx.doi.org/10.5935/abc.2014S003 >. Acesso em: 19 de março de 2018.

IBGE - Instituto Brasileiro de Geografia e Estatística. Práticas de Esporte e Atividades Física. PNAD, 2015. Brasília-DF, 2015. Disponível em: <https://biblioteca.ibge.gov.br/visualizacao/livros/liv100364.pdf>. Acesso em: 25/01/2018.

KEMPERMANN, G.H. KUHN G E GAGE, F.H.More hippocampal neurons in adult mice living in an enriched environment. em Nature, vol. 386, págs. 493495, 3 de abril de 1997.

MATTOS,A.S.;ANDRADE,A.;LUFT,C.Di B.A Contribuição da atividade física no tratamento da depressão. Sportes.com/ Revista Digital - Buenos Aires Ano 10 - N 79 - Diciembre de 2004. Disponível em: <http://www.efdeportes. com/efd79/depres.htm>. Acesso em: 15/05/2017.

MOLINA,O.F. Estresse no cotidiano.Santa Cecília-SP: Editora Pancast,1996.

MCEWEN,B.; LASLEY,E.N. O fim do estresse como nós conhecemos. Rio de Janeiro : Editora Nova Fronteira, 2003.

MATSUDO,S.M.M.Envelhecimento,Atividade Física e Saúde.São Paulo:Boletim do Instituto de Saúde de São Paulo, 2009.

PRAAG, H.V. SCHINDER, A.F. CHRISTIE, B.R.TONI, N. PALMER, T.O. E GAGE, F.H. Functional neurogenesis in the adult hippocampus. Nature, vol. 415, págs. 1030-1034,28 de fevereiro de 2002.

REHEN, S E PAULSEN, B.A fonte da renovação., Mente\&Cérebro, edição 178, novembro de 2007.

ROLIM, F.S; FORTI, V.A. Atividade física e os domínios da qualidade de vida e do autoconceito no processo de envelhecimento. Dissertação (Mestrado em Educação Física)Dissertação (Mestrado em Educação). Programa de Pós-Graduação em Educação Física. Universidade de Campinas, Campinas, Unicamp, 2005.

TAMAYO, A. (Org.). Estresse e cultura organizacional. São Paulo: Casa do Psicólogo: All Books, 2008. Coleção Trabalho Humano. 
TAMAYO, A et. al. A influência da atividade física regular sobre o autoconceito. Revista Estudos de Psicologia n.6 (2) 155-165, Universidade de BrasíliaDF, 2001 